Orta ve şiddetli seviyelerde bor toksisitesinin Arabidopsis thaliana'da miR393 ekspresyonu üzerine etkisi

\author{
Ceyhun Kayıhan* \\ Başkent Üniversitesi, Fen Edebiyat Fakültesi, Moleküler Biyoloji ve Genetik Bölümü, 06790, Ankara, Türkiye \\ ORCID ID orcid.org/0000-0003-1684-4147
}

\section{MAKALE BİLGISI}

Makale Geçmişi:

İlk gönderi 20 Ağustos 2020

Kabul 11 Kasım 2020

Online 29 Aralık 2020

\section{Araştırma Makalesi}

DOI: 10.30728/boron.783209

\section{Anahtar kelimeler:}

Arabidopsis thaliana,

Bor,

Ekspresyon

miR393,

Toksisite.

\section{ÖZET}

Bitkilerde korunmuş olan mikroRNA (miRNA) ailelerinden biri olan miR393, birçok kritik gelişimsel süreçlerde rol oynamaktadır. Bu çalışmada, Stem-Loop (SL) kantitatif ters transkripsiyon polimeraz zincir reaksiyonu yöntemi ile $1 \mathrm{mM}$ (1B) ve $3 \mathrm{mM}$ (3B) borik aside maruz kalan Arabidopsis thaliana'da miR393'ün ekspresyon seviyeleri belirlenmiştir. Ayrıca, miR393'ün $A$. thaliana'da hedeflediği genler ve bu genlerin Gen Ontoloji (GO) zenginleştirme analizi yapılmıştır. A. thaliana bitkisinde toksik seviyelerde bor uygulamaları sonrası, $A$. thaliana fidelerinin gelişiminlerinde gerileme ve fidelerin yaprak uçlarında kloroz gözlemlenmiştir. A. thaliana'da 1B uygulaması miR393 ekspresyonu 2,9 kat artırırken, 3B uygulaması 2,7'lik bir artışa sebep olmuştur. miR393'ün 5' ve 3' ucundaki olgun dizilere göre başlıca hedef genleri; auxin sinyal F-box, S-adenosil-L-metiyoninbağımlı metiltransferaz süper familya proteinlerini, Kinezin benzeri kalmodulin-bağlanma proteinlerini, Lösin-zengin reseptör benzeri protein kinaz familya proteinlerini, 1-deoksi-Dksilüloz 5-fosfat sentaz enzimini, ARM tekrar süper familya proteinlerini ve myb-benzeri HTH transkripsiyonel regülatör familya proteinlerini kodlayan genler ve bHLH ve WRKY33 transkripsiyon faktörleridir.Öte yandan, miR393'ün hedeflediği genlerin GO zenginleştirme analizine göre başlıca Biyolojik Süreçleri şu şekildedir: Oksin ile aktifleşmiş sinyal yolağı, oksin uyarısına hücresel cevap, çeşitli gelişim süreçleri ve farklı hücresel cevaplardır. Moleküler Fonksiyonlar ise, oksin bağlayıcı, inositol heksakisfosfat bağlayıcı ve hormon ve alkol bağlayıcı şeklinde kategorize edilebilir. Sonuç olarak, bor toksisitesi altında tespit edilen büyüme geriliği, miR393 hedefli oksin regülasyonu ve bHLH gibi ilişkili transkripsiyon faktörleri ile ilgili olabilir.

\title{
Effect of of boron toxicity on miR393 expression at moderate and severe levels in Arabidopsis thaliana
}

\section{ARTICLE INFO}

Article history:

Received August 20, 2020

Accepted November 11, 20200

Available online December 29, 2020

\section{Research Article}

DOI: 10.30728/boron.783209

\section{Keywords:}

Arabidopsis thaliana,

Boron,

Expression,

mir393,

Toxicity.

\section{ABSTRACT}

miR393, one of the microRNA (miRNA) families preserved in plants, plays a role in many critical developmental processes. In this study, expression levels of miR393 were determined in Arabidopsis thaliana exposed to $1 \mathrm{mM}$ (1B) and $3 \mathrm{mM}$ (3B) boric acid by Stem-Loop (SL) quantitative reverse transcription polymerase chain reaction method. In addition, genes targeted by miR393 in A. thaliana and Gene Ontology (GO) enrichment analysis of these genes were performed. After application of toxic levels of $B$ in $A$. thaliana plant, a decrease in the growth of $A$. thaliana seedlings and chlorosis on the leaf tips of the seedlings were observed. While $1 \mathrm{~B}$ application caused a 2.9 fold increase in miR393 expression, 3B application caused a 2.7 fold increase in this expression. According to the mature sequences at the 5 'and 3 ' ends of miR393, the main target genes are; genes coding Auxin signaling F-box, S-adenosyl-L-methionine-dependent methyltransferases superfamily protein, kinesin-like calmodulin-binding protein, Leucine-rich receptor-like protein kinase family protein, 1-deoxy-D-xylulose 5-phosphate synthase 3 , ARM repeat superfamily protein, myb-like HTH transcriptional regulator family protein and $\mathrm{bHLH}$, and WRKY33 transcription factors. On the other hand, according to the GO enrichment analysis, the main Biological Processes of the genes targeted by miR393 are as follows: The auxin-activated signaling pathway, the cellular response to auxin, various developmental processes, and different cellular responses. Molecular functions can be categorized as auxin binding, inositol hexakisphosphate binding and hormone and alcohol binding. As a result, growth retardation detected under boron toxicity may be related to miR393 targeted auxin regulation and associated transcription factors such as bHLH. 


\section{Giriş (Introduction)}

Bor (B), bitkiler için mutlak gerekli mikro besin elementidir [1]. Bununla birlikte, yüksek bor seviyesi, dünyadaki önemli abiyotik stres faktörlerinden biridir ve bitki gelişimi ile mahsul verimini olumsuz etkilemektedir [2]. Birçok ülke, özellikle kurak veya yarı kurak topraklara sahip olanlar, aşırı bor sebebiyle verim kaybından muzdariptir [3]. Bor, büyüme için gerekli seviyenin çok az üstünde bile olsa, birçok bitki için kolayca toksik olabilir [4]. Bor toksisitesi, hücre duvarı yapısında değişikliklere ve borun biyolojik moleküllerin ribozlarına bağlanması nedeniyle, hücre bölünmesinin ve gelişiminin bozulasına neden olur [5]. Tipik olarak, toksik bor, gövde ve kök büyümesinde inhibisyona ve eski yaprakların uçlarında ve kenarlarında klorotik veya nekrotik bölgelerle ayırt edilen yaprak yanmasına yol açar $[6,7]$. Çoğu bitki türünde, bor kökler tarafından emildikten sonra, ksileme yüklenir ve transpirasyon akışı yoluyla gövdeye geçer ve yeniden dağıtılmadan eski yapraklarda birikir; bu nedenle yapraklardaki bor içeriği ile toksisite semptomlarının şiddeti arasında doğrudan bir ilişki vardır [8]. Bor toksisitesi altında köke ve gövdeye özgü akuaporinleri kodlayan genlerin aşağı regülasyonu, hücreden hücreye su hareketinde azalmaya ve gövdelere su akışında azalmaya neden olmaktadır [9]. Bu nedenle, yaprak ve gövdede bor toksisite semptomları köklerden daha şiddetlidir. Borun toksik etkileri devam ederse, boron cis konfigürasyonlu moleküllerde çoklu hidroksil gruplarına karşı yüksek reaktivitesi nedeniyle azot ve şeker metabolizmasının baskılanma durumu gelişir [10]. Bu sitotoksik etkiler, metabolik bozukluğa ve oksidatif strese neden olur [10]. Öte yandan, aşırı bor varlığında, bitki inhibisyonu nedenlerinden bir diğeri foto-oksidatif strestir [5] ve oksidatif stres sonucu reaktif oksijen türlerinin (ROS) aşırı birikimi, pigmentleri, lipidleri, nükleik asitleri, proteinleri ve inaktive edici enzimleri oksitleyerek hücre ölümüne neden olabilir [11]. Bitkiler, ROS birikimine karşı antioksidan enzimleri içeren süpürücü mekanizmalarına sahiptir. İlişkili olarak, domateste, antosiyaninin ve flavonoidin artmış seviyesi [12], fesleğende daha yüksek fenolik içerik [13], ve nohutta ve soya fasülyesinde, süperoksit dismutaz (SOD; EC 1.15.1.1), katalaz (CAT; EC 1.11.1.6), ve askorbat peroksidaz (APX; EC 1.11.1.11) aktivitelerinde anlamlı artışlar [14], toksik bor koşulları altında belirlenmiştir.

Bor toksisitesine karşı bitki toleransı, türler hatta çeşitler arasında bile büyük farklılıklar göstermektedir [3]. Bitkilerde bor toksisitesine karşı toleransın altında yatan mekanizmalar hala tartışmalıdır. Otsu bitki türleri için önerilen en yaygın kabul gören teori, bor dışa akış taşıyıcıları yoluyla hücreler arası bor seviyelerinin azaltılmasıdır. Örneğin; arpada (Hordeum vulgare), köklerdeki bor dışa akım taşıyıcısı BOR1'in yukarı regülasyonu, borun topraktan emilimini azaltır [15]. Buna karşın; BOR1'e homolog olan BOR2'nin yapraklardaki yukarı regülasyonu, borun simplastlar- dan apoplastlara taşınmasına neden olur [16]. Benzer şekilde, köklerdeki başka bir dışarı akış taşıyıcısı olan nodulin benzeri iç proteinin (NIP) aşağı regülasyonu da borun köklerden gövdelere taşınmasını azaltarak, yer üstü bitki parçalarında bor birikimini azaltmaktadır [17]. Öte yandan, yakın bir zamanda yapılan fizyolojik bir çalışma fesleğenin bor toksisitesine karşı tolerans mekanizmalarında yaprak antosiyaninleri tarafından foto korumanın rol oynadığı göstermiştir [18]. Bu durum, bor toksisitesine karşı farklı mekanizmaların rol oynayabileceğini göstermiştir.

Omiks teknolojileri ile yapılan son moleküler çalışmalar, toksik borun yanıtları ve biyolojik yolaklarla olası ilişkileri hakkında önemli bilgiler sağlamıştır [19,20]. Önemli olarak, bu çalışmalarda, bor homeostazisinin WRKY, MYB ve NAC gibi transkripsiyon faktörlerindeki değişiklikler ile düzenlendiğini öne sürülmüştür. Ayrıca, temel heliks-döngü-heliks aile proteininin (bHLH) ekspresyon seviyesi, bor toksisitesi altında hassas ve tolerant buğday çeşitlerinin yaprak ve kök dokularında aşağı yönlü regüle olduğu ve bu transkripsiyon faktörünün, bitkilerdeki bor toksisitesi yanıtına katılabileceği bildirilmiştir [20]. Bununla birlikte, stres sırasında genlerin nasıl regüle olduğu sorusunu cevaplamak, yeni genler bulmak kadar önemlidir [21]. Bundan dolayı, mikroRNA'lar (miRNA), post-transkripsiyonel seviyede gen ekspresyonunun anahtar düzenleyicileri olarak, stres ağını keşfetmek için iyi adaylardır. Bu kodlanmayan küçük RNA'lar, 21 ila 24 nükleotid uzunluğunda, bitkilerde geniş bir dağılıma sahiptir. Bu miRNA'lar, bitkilerde, doğrudan hedef mRNA'yı susturarak ya da hedef mRNA'nın translasyonunu inhibe ederek genlerin ekspresyonlarını negatif yönlü regüle ederler [22]. Kanıtlar, bitki miRNA'larının bitki büyümesinin ve gelişiminin düzenlenmesinde ve ayrıca biyotik ve abiyotik streslere yanıtta çok önemli bir rol oynadığını göstermektedir [23]. Örneğin, A. thaliana'da miR399'un UBC24 transkript seviyesini düzenleyerek fosfor $(P)$ homeostazını sağladığı deneysel olarak kanıtlanmıştır [24]. Buna karşın, miR395, sırasıyla APS ve SULTR2;1'i hedefleyerek, sülfat (S) birikimi ve dağılımını düzenlenmesine aracılık etmektedir [25]. Benzer şekilde, artan kanıtlar, bitki miRNA'larının bor streslerine yanıtta çok önemli bir rol oynadığını göstermektedir [26]. Örneğin, daha önce yapılan bir çalışmada, narenciye yapraklarında miR397a'nın ksilemin ikincil hücre duvarı biyosentezini düzenleyerek bor toksisitesinin bitkiye olan etkisinin azaltılmasında rol oynadığı bildirilmiştir [27]. Bu nedenle, bitkide bor toksisitesine cevaben değişen miRNA'ların belirlenmesi tolerans mekanizmasının belirlenmesi için önem arz etmektedir. Bu çalışmada, literatürde ilk defa oksin reseptörleri TIR1, AFB1, AFB2 ve AFB3'ü ve aşağı yönlü regüle olduğu daha önce belirlenen bHLH transkripsiyon faktörünü hedefleyen miR393'ün ekspresyon seviyeleri 1 $\mathrm{mM}(1 \mathrm{~B})$ ve $3 \mathrm{mM}$ (3B) borik aside maruz kalan $A$. thaliana'da olgun miRNAları tespit etmek ve çoğaltmak için önemli bir strateji olan Stem-loop (SL) kan- 
titatif ters transkripsiyon polimeraz zincir reaksiyonu yöntemi [28,29] ile belirlenmiştir. Bu yöntemde, bir saç tokası yapısı olarak tasarlanan SL primeri, miRNA'ya komplementer olan 3' çıkıntıya sahiptir. Daha sonra, miRNA-spesifik primerler ve bir evrensel primer, olgun miRNA'nın polimeraz zincir reaksiyonu (PZR) ile amplifikasyonu için kullanılır [30]. Ayrıca, bu çalışmada miR393'ün A. thaliana'da diğer hedeflediği genler ve bu genlerin Gen Ontoloji (GO) Zenginleştirme analizi yapılmıştır.

\section{Malzemeler ve yöntemler (Materials and methods)}

\subsection{Büyüme koşulları ve bor uygulamaları (Growth conditions and boron treatments)}

Büyütme koşulları ve bor uygulamaları için Arabidopsis ( $A$. thaliana Columbia ekotipi) tohumlarının, önce \%70'lik etil alkol ile 2 dakika, ardından \%15'lik sodyum hipoklorit çözeltisi ile 10 dakika yıkanarak yüzeyleri sterilize edilmiştir. Ardından tohumlar distile su ile 3 kez durulanmıştır ve normal $(100 \mu \mathrm{M})$ ve toksik (1 mM ve $3 \mathrm{mM} \mathrm{H}_{3} \mathrm{BO}_{3}$ ) B konsantrasyonları içeren MS besiyerine [31] transfer edilmiştir. 3 günlük, $4^{\circ} \mathrm{C}$ 'deki vernelizasyonun ardından çimlenme ve büyüme $22^{\circ} \mathrm{C}$ 'de iklim kabininde, 16/8-h ışık fotoperiyodu ile gerçekleştirilmiştir. İki haftanın ardından fideler hasat edilmiştir ve ileri analizler için kullanılmıştır.

\subsection{Kantitatif gerçek zamanlı PZR koşulları (Quan- titative real-time PCR conditions)}

İki haftalık $A$. thaliana fidelerinden TRIzol reaktifi (Ambion) ile toplam RNA izole edilmiştir. İzolasyon protokolü şu şekildedir: 0,2 gram $A$. thaliana yaprakları sıvı nitrojen ile havanda öğütülmüş ve toz haline gelen yaprak örneği önceden soğutulmuş eppendorf tüplerine transfer edilmiştir. Ardından, $1 \mathrm{ml}$ TRIzol reaktifi tüplere eklenmiş ve 15 dakika boyunca oda sıcaklığında tüpler vorteks ile karıştırılmış ve devamında tüpler 5 dakika boyunca oda sıcaklığında maksimum hızda santrifüjlenmiştir. Santrifüj sonrası elde edilen süpernatanttan $900 \mu$ yeni tüplere aktarılmış ve üzerine $180 \mu \mathrm{l}$ kloroform eklenmiş ve tüpler vortekslenerek 3 dakika boyunca oda sıcaklığında inkübe edilmiştir. İnkübasyon sonunda tüpler, $4^{\circ} \mathrm{C}$ 'de maksimum hızda 15 dakika santrifüjlenmiştir. Elde edilen süpernatant$\tan 450 \mu \mathrm{l}$ yeni tüplere aktarılmış ve üzerine $200 \mu \mathrm{l}$ kloroform eklenmiştir. Tüpler vorteklenerek oda sıcak- lığında 3 dakika boyunca inkübe edilmiştir. Ardından, tüpler, oda sıcaklığında 5 dakika boyunca maksimum santrifüjlenmiştir ve üst fazdan $400 \mu$ l alınarak yeni tüpe transfer edilmiştir ve üzerine eşit hacimde izopropanol eklenmiş ve tüpler birkaç kez tersyüz edilerek, 10 dakika boyunca oda sıcaklığında inkübe edilmiştir. Tüpler 10 dakika boyunca oda sıcaklığında maksimum hızda santrifüjlenmiş ve elde edilen pelet $1 \mathrm{ml}$ \%75'lik etanol ile 3 dakika boyunca yıkanmıştır. Daha sonra, 5 dakika boyunca oda sıcaklığın maksimum hızda santrifüjlene pelet 10 dakika boyunca kurumaya bırakılmıştır. Son olarak, kurutulan pelet üzerine $50 \mu$ l Dietil Pirokarbonat'lı su eklenmiş ve $65^{\circ} \mathrm{C}$ 'de 15 dakika boyunca inkübe edilerek çözülmüştür. RNA'nın sağlamlığı ve kalitesini kontrol etmek için agaroz jel elektroforezi kullanılmıştır. Ardından RNA saflığı ve konsantrasyonu NanoDrop (Denovix, ABD) ile belirlenmiştir. İzole edilen toplam RNA'lar kullanıma kadar $-80^{\circ} \mathrm{C}^{\prime}$ de saklanmıştır.

miRBase veritabanı, miR393 sekansını elde etmek üzere kullanılmıştır. SL-geri transkripsiyon ve ileri primerler [32] protokolüne uygun bir şekilde özel olarak tasarlanmıştır. miR393 için primer sekansları Tablo 1'de verilmiştir. miR393 ekspresyonu, kantitatif gerçek zamanlı PZR (qRT-PCR) metodu ile belirlenmiştir [33]. Öncelikle, $1 \mu \mathrm{g}$ RNA, RNaz içermeyen su, $2 \mu \mathrm{L}$ SL primeri içeren $12 \mu L^{\prime}$ 'lik karışımlar hazırlanmıştır. Bu karışımlar, 5 dakika $65^{\circ} \mathrm{C}$ 'de, ardından 2 dakika buzda inkübe edilmiştir. Sonrasında, $5 \mathrm{X}$ reaksiyon tamponu, RiboLock RNaz inhibitörü (20 U/ $\mu \mathrm{L}), 10 \mathrm{mM}$ dNTP ve ters transkriptaz karışımlara eklenmiştir. Karışımlar 30 dakika boyunca $16^{\circ} \mathrm{C}$ 'de inkübe edilmiştir ve 60 döngü boyunca $30^{\circ} \mathrm{C}$ 'de $30 \mathrm{~s}, 42^{\circ} \mathrm{C}$ 'de $30 \mathrm{~s}$ ve $50^{\circ} \mathrm{C}$ 'de $1 \mathrm{~s}$ olarak şekilde atımlı geri transkripsiyona maruz bırakılmıştır. Ardından tüpler $70^{\circ} \mathrm{C}$ 'de 5 dakika inkübe edilmiştir. qRT-PCR analizleri için, $1 \mu \mathrm{L}$ cDNA, $7 \mu \mathrm{L} 2 \mathrm{X}$ Master Mix (Thermo Scientific) ve final konsantrasyon $0,3 \mu \mathrm{M}$ olacak şekilde primerler eklenerek total hacim nükleazsız su ile $15 \mu L^{\prime} y e$ tamamlanmıştır. qRT-PCR koşulları, $95^{\circ} \mathrm{C}$ 'de 10 dakika ilk denatürasyon, ardından 40 döngü $95^{\circ} \mathrm{C}$ 'de $15 \mathrm{~s}, 5^{\circ} \mathrm{C}$ 'de $30 \mathrm{~s}, 72^{\circ} \mathrm{C}$ 'de $30 \mathrm{~s}$ olarak belirlenmiştir. Erime eğrisi (melting curve) 40 döngü sonrası $60-95^{\circ} \mathrm{C}$ 'de analiz edilmiştir. Normalizasyon aktin (ACT2) geni kullanılarak gerçekleştirilmiştir [20] ve $2^{-\Delta \Delta C t}$ her bir karşılaştırmada ekspresyon kat farklılıklarını belirlemek üzere kullanıımıştır.

Tablo 1. miR393 ekspresyon analizi için kullanılan primerler (Primers used for miR393 expression analysis).

\begin{tabular}{ll}
\hline Primer İsmi & $\mathbf{5}, \mathbf{- 3}$ yönünde sekans \\
\hline miR393-SL-RT & GTCGTATCCAGTGCAGGGTCCGAGGTATTCGCACTGGATACGACGGATCA \\
miR393_F & CGTAATTCCAAAGGGATCGCAT \\
Universal_R & GTGCAGGGTCCGAGGT \\
ACT2_F & CTTGACCTTGCTGGACGTGA \\
ACT2_R & AATTTCCCGCTCTGCTGTTG
\end{tabular}




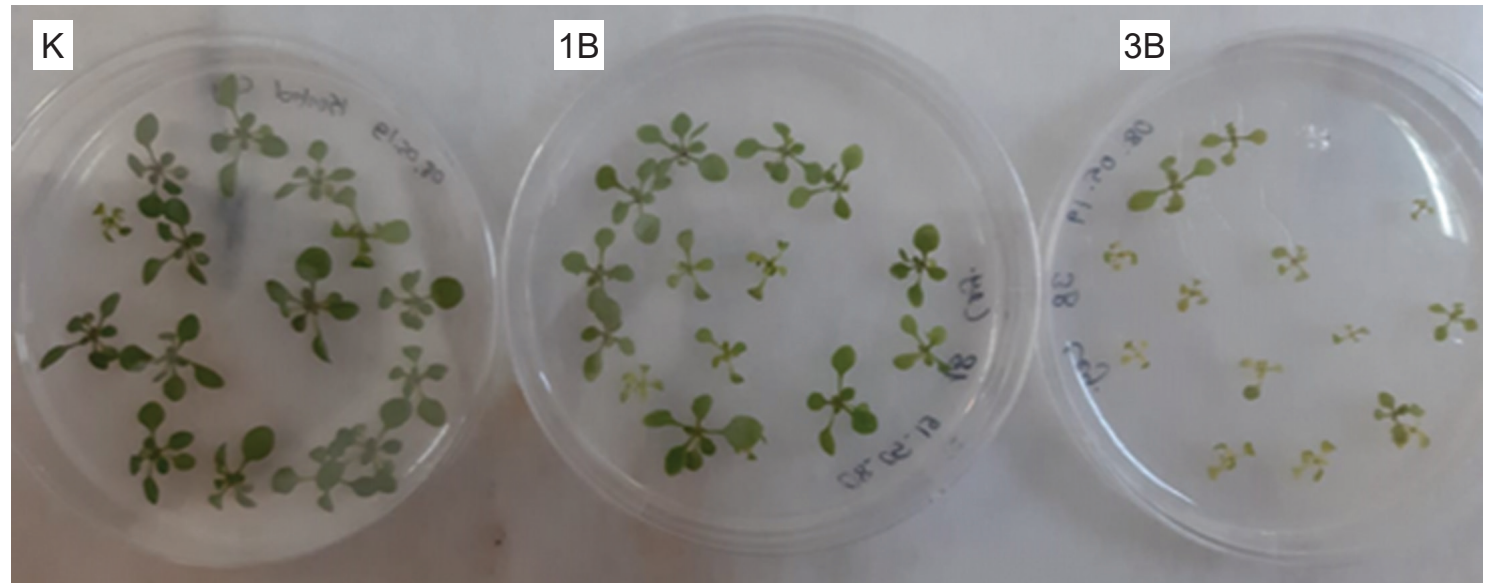

Şekil 1. Toksik $B$ uygulamalarına maruz kalmış Arabidopsis thaliana fidecikleri. K: kontrol, $1 \mathrm{~B}: 1 \mathrm{mM} \mathrm{H}_{3} \mathrm{BO}_{3}$ uygulaması, $3 \mathrm{~B}$ : $3 \mathrm{mM} \mathrm{H}_{3} \mathrm{BO}_{3}$ uygulaması.(Arabidopsis thaliana seedlings exposed to toxic $\mathrm{B}$ treatments. K: control, $1 \mathrm{~B}: 1 \mathrm{mM} \mathrm{H}_{3} \mathrm{BO}_{3}$ treatment, $3 \mathrm{~B}: 3$ $\mathrm{mM} \mathrm{H}_{3} \mathrm{BO}_{3}$ treatment).

\section{3. miR393 hedef genlerinin bilgisayımsal tahmi- ni ve GO zenginleștime analizi (Computational pre- diction of target genes of miR393 and GO enrichment analysis)}

A. thaliana'da miR393'ün hedeflerini belirlemek için, olgun miRNA dizileri miRBase veri tabanı kullanılarak (sürüm 22.1, http://www.mirbase.org/) belirlenmiştir [34]. Daha sonra, bu olgun miR393 dizileri kullanılarak miR393 hedef genleri psRNATarget veri tabanında belirlenmiştir (version 2, http://plantgrn.noble.org/ psRNATarget/) [35].

miR393'ün belirlenen hedef genlerinin GO zenginleştime analizi 10.08.2020 tarihinde güncellenen PANTHER veritabanı kullanılarak (sürüm 14, http://geneontology.org/) yapılmıştır [36]. Referans liste A. thaliana seçilerek yapılmıştır. $\mathrm{GO}$ biyolojik süreç ve moleküler fonksiyon sonuçları test tipi Fisher's exact ve doğrulama FDR seçilerek yapılmıştır $(P<0,05)$.

\section{4. İstatistiksel analizler (Statistical analyses)}

qRT-PCR deneyleri, dört biyolojik tekrar olarak gerçekleştirilmiştir $(n=4)$. Veriler istatistiksel olarak $t$-testinin parametrik olmayan versiyonu kullanarak analiz edilmiştir. Öte yandan, yaprak alanı verileri, dört biyolojik tekrar ve her tekrardan en az 10 bitki olacak şekilde Java tabanlı ImageJ programı kullanılarak elde edilmiştir. Yaprak alanı verileri, SPPS istatistik programı kullanılarak Tek Yönlü Varyans Analizi (ANOVA) ile analiz edilmiştir. Veriler, ortalama ve standart hata birlikte olacak şekilde verilmiştir.

\section{Bulgular (Results)}

A. thaliana bitkisinde toksik seviyelerde bor uygulamaları sonrası, A. thaliana fidelerinin gelişimlerinde gerileme ve fidelerin yaprak uçlarında kloroz gözlemlenmiştir (Şekil 1). Hatta beklendiği üzere, yaprak alanı verilerine göre bor toksisitesinin artan konsantrasyonuna karşılık, $A$. thaliana yapraklarında kısmi sararma ve büyüme geriliği artmıştır (Şekil 2). Öte yandan, $A$. thaliana'da 1B uygulaması miR393 ekspresyonu 2,9 kat artırırken, 3B uygulaması 2,7'lik bir artışa sebep olmuştur (Şekil 3).

miR393'ün 5' ve 3' ucundaki olgun dizilere göre (5p ve $3 p$ ) başlıca hedef genleri; auxin sinyal F-box, S-adenosil-L-metiyonin- bağımlı metiltransferaz süper familya proteinlerini kodlayan genler, Kinezin benzeri kalmodulin-bağlanma proteinlerini kodlayan genler, Lösin-zengin reseptör benzeri protein kinaz familya proteinlerini kodlayan genler, 1-deoksi-D-ksilüloz 5-fosfat sentaz enzimini kodlayan gen, ARM tekrar süper familya proteinlerini kodlayan genler, myb-benzeri HTH transkripsiyonel regülatör familya proteinlerini kodlayan genler ve bHLH, ve WRKY33 transkripsiyon faktörleridir (Tablo 2). Öte yandan, miR393'ün hedefle-

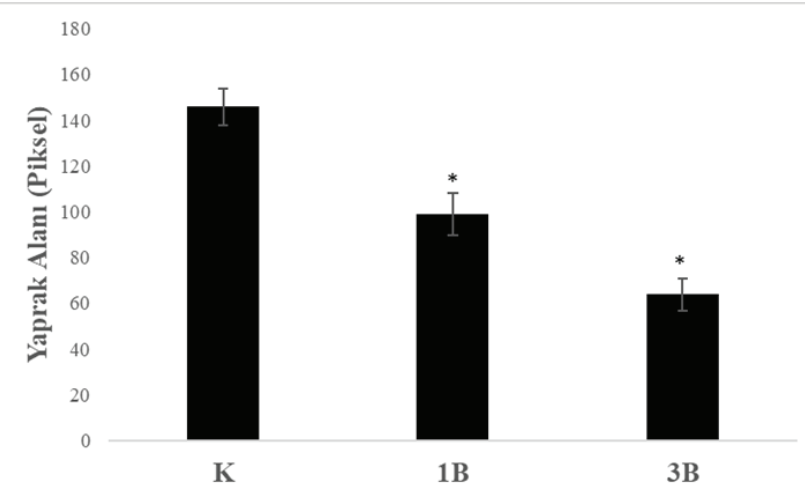

Şekil 2. Toksik B uygulamaları altında Arabidopsis thaliana'nın yaprak alanında (piksel) değişim. K: Kontrol, 1B: $1 \mathrm{mM} \mathrm{H}_{3} \mathrm{BO}_{3}$ uygulaması, 3B: $3 \mathrm{mM} \mathrm{H}_{3} \mathrm{BO}_{3}$ uygulaması. Ondört bağımsız biyolojik tekrardan gelen ortalama ve standart hata gösterilmektedir $(p<0,05)$. Hata çubukları üzerindeki yıldız işareti $\left(^{*}\right)$ kontrole göre istatistiksel olarak anlamlı olduğunu göstermektedir. (Changes in leaf area (pixel) in Arabidopsis thaliana under toxic $\mathrm{B}$ treatments. $\mathrm{K}$ : control, 1B: 1 $\mathrm{mM} \mathrm{H} \mathrm{BO}_{3}$ treatment, 3B: $3 \mathrm{mM} \mathrm{H} \mathrm{BO}_{3}$ treatment. The mean and standard error from fourteen independent biological replicates are shown $(p<0.05)$. An asterisk above the error bars represents significant differences between control and B-toxicity-treated samples.). 


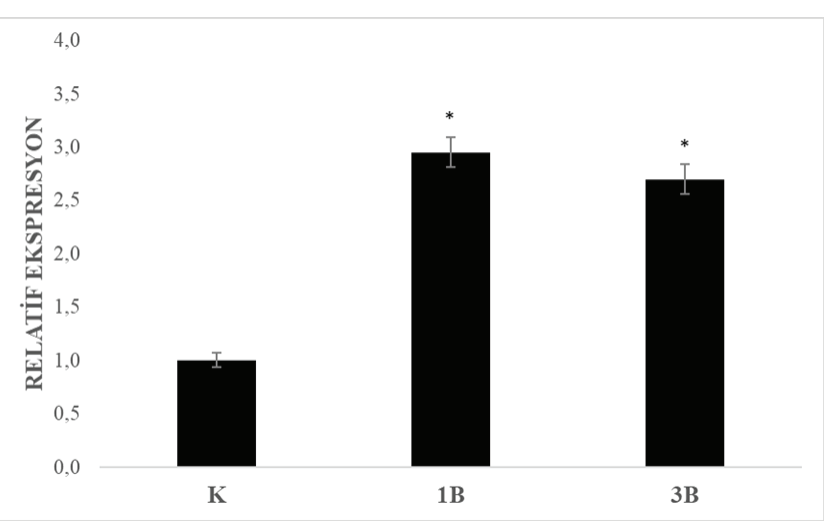

Şekil 3. Arabidopsis thaliana'da toksik B uygulamaları altında miR393'ün ekspresyon seviyelerindeki değişim. K: Kontrol, 1B: $1 \mathrm{mM} \mathrm{H}_{3} \mathrm{BO}_{3}$ uygulaması, 3B: $3 \mathrm{mM} \mathrm{H}_{3} \mathrm{BO}_{3}$ uygulaması. Üç bağımsız biyolojik tekrardan gelen ortalama ve standart hata gösterilmektedir $(p<0,05)$. Hata çubukları üzerindeki yıldız işareti $\left(^{*}\right)$ kontrole göre istatistiksel olarak anlamlı olduğunu göstermektedir. (Changes in expression level of miR393 in Arabidopsis thaliana under toxic $\mathrm{B}$ treatments. $\mathrm{K}$ : control, 1B: $1 \mathrm{mM} \mathrm{H}_{3} \mathrm{BO}_{3}$ treatment, 3B: $3 \mathrm{mM} \mathrm{H}_{3} \mathrm{BO}_{3}$ treatment. The mean and standard error from three independent biological replicates are shown $(p<0.05)$.) An asterisk above the error bars represents significant differences between control and B-toxicity-treated samples.

diği genlerin GO zenginleştirme analizine göre başlıca Biyolojik Süreçleri şu şekildedir: Polen matürasyonu, Oksin ile aktifleşmiş sinyal yolağı, Oksin uyarısına hücresel cevap, SCF-bağımlı proteozomal ubikuitinbağımlı protein katabolik süreç, Stamen gelişimi, Floral organ gelişimi, Gelişimsel matürasyon, Proteazom aracılı ubikuitin bağımlı protein katabolik süreç, Çiçek gelişimi, Oksin yanıtı, Hormon aracılı sinyal yolağı, Hormon uyarısına hücresel cevap, Organik maddeye hücresel cevap, Hücresel makromolekül katabolik süreç, Hormon cevabı, Endojen uyaran cevabı ve Organik madde cevabı (Tablo 3). miR393'ün hedeflediği genlerin Gen Ontoloji (GO) Zenginleştirme analizine göre Moleküler Fonksiyonları, Oksin bağlayıcı, İnositol heksakisfosfat bağlayıcı ve Hormon ve alkol bağlayıcı şeklinde kategorize edilebilir (Tablo 4).

\section{Tartışma (Discussion)}

Bitki miRNA'ların 2002'de önemli bir posttranskripsiyonel düzenleyici olarak bulunuşunun ardından [37] bitki büyüme ile gelişiminde önemli rollerinin önerilmesiyle [38], çevresel strese cevaba olan katkılarının ileri ki çalışmalarla incelenmesi $[39,40]$ miRNA'ları gündemde önemli bir yere getirmiştir. Bu çalışmalarda miRNA'ların bitkilerdeki birçok çevresel stresin adaptif cevabında bulunduğunu öne sürülmüştür $[41,42]$. Literatürde ilk olacak şekilde, arpa [43] ve turunçillerde [44] bor toksisitesine cevapta bazı miRNA'nın değiştiği belirlenmiştir. Ayrıca, çok yakın zamanda, toksik bor koşullarına maruz kalan $A$. thaliana'da jasmonat ve etilen mekanizmalarıyla ilişkili olan transkripsiyon faktörlerinin hedeflendiği miRNA'ların ekspresiyon seviyeleri belirlenmiştir [45]. Buna göre; miR159, miR319, miR394 ve miR172 ekspresyon seviyeleri orta seviyede bor toksisitesi altında dramatik bir şekilde artarken, daha şiddetli B toksisitesi uygulaması altında ilginç bir şekilde bu miRNA'ların ekspresyonu kontrol koşullarına göre değişmediği önerilmiştir. Bu çalışmada ise; literatürde ilk defa miR393'ün ekspresyon seviyesi $A$. thaliana'da 1 ve $3 \mathrm{mM} \mathrm{B}$ koşulları altında belirlenmiştir. Buna göre $A$. thaliana'da orta ve șiddetli seviyelerde toksik bor uygulamaları, miR393'ün ekspresiyonunu yaklaşık 3 kat arttırmıştır. A. thaliana'da mirR393'ün başlıca hedefleri oksin reseptörlerini kodlayan F-box genleri (Transport Inhibitor Response Protein1 (TIR1), Auxin Signaling F Box Protein 2 (AFB2 ve AFB3)) ve bHLH transkripsiyon faktörüdür [46-48] (Tablo 3). İlişkili olarak, bir önceki çalışmamızda bHLH ekspresyon

Tablo 2. miR393'ün olası hedeflediği genlerden bazıları. ath-miR393a-5p: UCCAAAGGGAUCGCAUUGAUCC,

ath-miR393a-3p: AUCAUGCUAUCUCUUUGGAUU, AGI: Arabidopsis Genome Initiative, (Some of the possible target genes of miR393).

\begin{tabular}{cccl}
\hline miRNA & $\begin{array}{c}\text { Hedef Gen } \\
\text { AGI Kodu }\end{array}$ & $\begin{array}{c}\text { Beklenen } \\
\text { Değer }\end{array}$ & \\
\hline ath-miR393a-5p & AT1G12820 & 1.0 & auxin sinyal F-box 3 (AFB3) \\
ath-miR393a-5p & AT3G26810 & 1.0 & auxin sinyal F-box 2 (AFB2) \\
ath-miR393a-5p & AT3G62980 & 1.0 & F-box/RNI benzeri süper familya protein (TIR1) \\
ath-miR393a-3p & AT1G26850 & 2.0 & S-adenosil-L-metiyonin- bağıml metiltransferaz süper familya p1 \\
ath-miR393a-5p & AT4G03190 & 2.0 & GRR1-benzeri protein 1 (GRH1) \\
ath-miR393a-5p & AT3G23690 & 2.5 & basic helix-loop-helix (bHLH) DNA-bağlanma süper familya prc \\
ath-miR393a-3p & AT5G65930 & 3.0 & Kinezin benzeri kalmodulin-bağlanma proteini \\
ath-miR393a-3p & AT3G19420 & 3.0 & PTEN 2 \\
ath-miR393a-5p & AT2G38470 & 3.0 & WRKY DNA-bağlanma protein 33 (WRKY33) \\
ath-miR393a-5p & AT5G65700 & 3.0 & Lösin-zengin reseptör benzeri protein kinaz familya proteini (BA \\
ath-miR393a-5p & AT2G24210 & 3.0 & Terpen sentaz 10 (TPS10) \\
ath-miR393a-5p & AT5G11380 & 3.0 & 1- deoksi-D-ksilüloz 5-fosfat sentaz 3 (DXPS3) \\
ath-miR393a-3p & AT1G61350 & 3.5 & ARM tekrar süper familya proteini \\
ath-miR393a-3p & AT3G23020 & 3.5 & Tetrarikopeptid tekrar (TPR) benzeri süper familya proteini \\
ath-miR393a-3p & AT3G13040 & 3.5 & myb-benzeri HTH transkripsiyonel regülatör familya proteini \\
\hline
\end{tabular}


Tablo 3. miR393'ün hedeflediği genlerin GO zenginleştirme biyolojik süreç analizi (GO enrichment biological process analysis of genes targeted by miR393).

\begin{tabular}{lcc}
\hline GO: Biyolojik Süreç & $\begin{array}{c}\text { Kat } \\
\text { Zenginleştirme }\end{array}$ & $\begin{array}{c}\text { İşlenmemiş } \\
\text { p-değeri }\end{array}$ \\
\hline Polen matürasyonu & $>100$ & $9.42 \mathrm{E}-10$ \\
Oksin ile aktifleşmiş sinyal yolağı & $>100$ & $2.48 \mathrm{E}-08$ \\
Oksin uyarısına hücresel cevap & 90.93 & $1.23 \mathrm{E}-07$ \\
SCF-bağımlı proteozomal ubikuitin-bağımlı protein katabolik süreç & 72.53 & $2.92 \mathrm{E}-07$ \\
Androecium gelişimi & 72.53 & $7.77 \mathrm{E}-09$ \\
Stamen gelişimi & 72.53 & $7.77 \mathrm{E}-09$ \\
Floral whorl development & 39.46 & $1.48 \mathrm{E}-07$ \\
Floral organ gelişimi & 31.34 & $4.51 \mathrm{E}-07$ \\
Gelişimsel matürasyon & 30.93 & $7.90 \mathrm{E}-06$ \\
Proteazom aracılı ubikuitin bağımlı protein katabolik süreç & 24.18 & $2.04 \mathrm{E}-05$ \\
proteazomal protein katabolik süreç & 22.82 & $2.56 \mathrm{E}-05$ \\
Çiçek gelişimi & 21.51 & $2.78 \mathrm{E}-06$ \\
Üreme sürgün sistem gelişimi & 20.64 & $3.39 \mathrm{E}-06$ \\
Oksin yanıtı & 20.38 & $3.95 \mathrm{E}-05$ \\
Hormon aracılı sinyal yolağı & 18.00 & $6.54 \mathrm{E}-06$ \\
Polen gelişmi & 17.61 & $6.92 \mathrm{E}-05$ \\
Gametofit gelişimi & 16.52 & $9.88 \mathrm{E}-06$ \\
\hline
\end{tabular}

Tablo 4. miR393'ün hedeflediği genlerin GO zenginleştirme moleküler fonksiyon analizi. (GO enrichment molecular function analysis of genes targeted by miR393).

\begin{tabular}{lcc}
\hline GO: Moleküler Fonksiyon & $\begin{array}{c}\text { Kat } \\
\text { Zenginleştirme }\end{array}$ & $\begin{array}{c}\text { İşlenmemiş } \\
\text { p-değeri }\end{array}$ \\
\hline Oksin bağlayıcı & $>100$ & $6.40 \mathrm{E}-11$ \\
Inositol heksakisfosfat bağlayıcı & $>100$ & $1.14 \mathrm{E}-09$ \\
Hormon bağlayıcı & $>100$ & $7.54 \mathrm{E}-09$ \\
Alkol bağlayıcı & $>100$ & $1.58 \mathrm{E}-08$ \\
\hline
\end{tabular}

seviyesi, bor toksisitesi altında hassas ve tolerant buğday çeşitlerinin yaprak ve kök dokularında aşağı yönlü regüle olduğu ve bu transkripsiyon faktörünün, bitkilerdeki bor toksisitesi yanıtına katılabileceği bildirilmiştir [20]. miR393 ve hedef genlerinin düzenleyici modülünün kök yapısının kontrolü [49], yaprak gelişiminin düzenlenmesi [50] ve normal bitki büyümesinin sağlanması [51] gibi oksin cevabını manipüle eden birçok fonksiyonu olduğu keşfedilmiştir [52]. Bu miRNA'nın aynı zamanda biyotik ve abiyotik stres ile yakından ilişkili olduğu belirlenmiştir [53,54]. Pirinçte yapılan benzer araştırmalar, miR393'ün biyolojik fonksiyonlarının ve oksin yolağı ile düzenlenme mekanizmasının yüksek bitkilerde korunmuş olduğunu kanıtlamıştır [55-57]. B toksisitesine benzer şekilde, miR393'ün A. thaliana'da [53], pirinçte [58] ve şeker kamışında (Saccharum spp.) [59] kuraklık stresi sırasında yukarı yönlü regüle olduğu bildirilmiştir.

miR393'ün hedefi, $A$. thaliana'da oksin reseptörü olan TIR1'i kodlar. TIR1 enzimi ubikitinasyon yolu ile Aux/ IAA proteinlerinin degredasyonunu destekleyerek oksin sinyallenmesinin pozitif bir regülatörüdür [60]. Ya- kın zamanda yapılan bir çalışmada miR393'ün aşırı eksprese edildiği pirinç fidelerinin büyümesinin 1 günlük kuraklık uygulamasıyla kontrol bitkilerine kıyasla bastırıldığı bildirmiştir [57]. miR393'ü aşırı eksprese eden pirinçler aynı zamanda sentetik oksin analog uygulamalarına karşı aşırı duyarlılık göstermiştir [57]. Bu nedenle, artan miR393 seviyeleri, oksin sinyallenmesini aşağı regüle eder ve kuraklık stresi altında bitki büyümesini azaltabilir. Ayrıca, miR393'ün inhibe edildiği transgenik $A$. thaliana bitkisinde yaban tipe göre AtTIR1, AtAFB1, AtAFB2, ve AtAFB3 ekspresyonları artmış ve bu transgenik bitkilerin tuz ve absisik ait streslerine karşı dirençleri artmıştır [61]. Dolayısıyla, A. thaliana bitkisinde miR393'ün kısmı de olsa fonksiyon kaybı tuz stresine karşı tolerans kazandırmıştır [61]. Kuraklık stresine ve tuz streslerine benzer şekilde, bor toksisitesi altında tespit edilen büyüme geriliği, miR393 hedefli oksin reseptör regülasyonu ve bHLH transkripsiyon faktörü ile ilişkili olabilir. Bu nedenle, miR393 inhibisyonuna yönelik yaklaşımlar, bor toksisitesine karşı tolerant bitkiler yetiştirme amacıyla kullanılabilir. 


\section{Sonuçlar (Conclusions)}

Sonuç olarak, bor toksisitesinin artan konsantrasyonuna karşılık, $A$. thaliana yapraklarında kısmi sararma ve büyüme geriliği artmıştır. Öte yandan, $A$. thaliana'da $1 \mathrm{~B}$ ve $3 \mathrm{~B}$ uygulamaları, miR393 ekspresyonunu 3 kata yakın artışa sebep olmuştur. Bor toksisitesi altında tespit edilen büyüme geriliği, miR393 hedefli oksin reseptör regülasyonu ve bHLH transkripsiyon faktörü ile ilişkili olabilir. Dolayısıyla, miR393 inhibisyonuna veya AtTIR1, AtAFB1, AtAFB2, ve AtAFB3 aşırı ekspresyonuna yönelik yaklaşımlar bor toksisitesine karşı tolerant bitkiler yetiştirme amacıyla kullanılabilir.

\section{Teşekkür (Acknowledgement)}

Bu çalışmanın oluşmasında desteklerinden dolayı Dr. Doğa Selin KAYIHAN'a ve öğrencilerim Su Naz MUTLU, Irmak YILMAZ ve Melis Vuslat TUNÇ'a teşekkür ederim.

\section{Kaynaklar (References)}

[1] Warington K., The effect of boric acid and borax on the broad bean and certain other plants, Ann. Bot., 37, 629-672, 1923.

[2] Landi M., Degl'Innocenti E., Pardossi A., Guidi L., Antioxidant and photosynthetic responses in plants under boron toxicity: a review, Am. J. Agric. Biol. Sci., 7 (3), 255-270, 2012.

[3] Nable R. O., Ba nuelos G. S., Paull J. G., Boron toxicity, Plant Soil, 193, 181-198, 1997.

[4] Mengel K., Kirkby E. A., Principles of Plant Nutrition, $5^{\text {th }}$ edition, Springer, Hollanda, 2001.

[5] Reid R., Hajes J. E., Post A., Stangoulis J. C. R., Graham R. D., A critical analysis of the causes of boron toxicity in plants, Plant Cell Environ., 25, 1405-1414, 2004

[6] Bennett W. F., Nutrient Deficiencies and Toxicities in Crop Plants, $1^{\text {st }}$ Edition, APS, A.B.D., 1993.

[7] Fitzpatrick K. L., Reid R. J., The involvement of aquaglyceroporins in transport of boron in barley roots, Plant Cell Environ., 32, 1357-1365, 2009.

[8] Reid R., Understanding the boron transport network in plants, Plant Soil, 385, 1-13, 2014.

[9] Macho-Rivero M. A., Herrera-Rodríguez M. B., Brejcha R., Schäffner A. R., Tanaka N., Fujiwara T., GonzálezFontes A., et al., Boron toxicity reduces water transport from root to shoot in Arabidopsis plants. Evidence for a reduced transpiration rate and expression of major PIP aquaporin genes, Plant Cell Physiol., 59, 841-849, 2018.

[10] Princi M. P., Lupini A., Araniti F., Longo C., Mauceri A., Sunseri F. Abenavoli M. R., Plant Metal Interaction, Chap. 5: Boron Toxicity and Tolerance in Plants: Recent Advances and Future Perspectives, Elsevier, 2016.
[11] Blokhina O., Virolainen E., Fagerstedt K. V., Antioxidants, oxidative damage and oxygen deprivation stress: a review, Ann. Bot., 91, 179-194, 2003.

[12] Cervilla L. M., Blasco B., Rios J. J., Rosales M. A., Sanchez-Rodriguez E., Rubio-Wilhelmi M. M., Romero L., et al., Parameters symptomatic for boron toxicity in leaves of tomato plants, J. Bot., 1-17, 2012.

[13] Pardossi A., Romani M., Carmassi G., Guidi L., Landi M., Incrocci L., Maggini R., et al., Boron accumulation and tolerance in sweet basil (Ocimum basilicum L.) with green or purple leaves, Plant Soil, 395, 375-389, 2015.

[14] Ardıc M., Sekmen A. H., Tokur S., Ozdemir F., Turkan I., Antioxidant response of chickpea plants subjected to boron toxicity, Plant Biol., 11, 328-338, 2009.

[15] Reid R. J., Identification of boron transporter genes likely to be responsible for tolerance to boron toxicity in wheat and barley, Plant Cell Physiol., 48, 1673-1678, 2007.

[16] Reid R. J., Fitzpatrick K. L., Redistribution of boron in leaves reduces boron toxicity, Plant Signaling Behav., 4 (11), 1091-1093, 2009.

[17] Schnurbusch T., Hayes J., Hrmova M., Baumann U., Ramesh S. A., Tyerman S. D., Langridge P., et al., Boron toxicity tolerance in barley through reduced expression of the multifunctional aquaporin HVNIP2;1, Plant Physiol., 153, 1706-1715, 2010.

[18] Landi M., Guidi L., Pardossi A., Tattini M., Gould, K. S., Photoprotection by foliar anthocyanins mitigates effects of boron toxicity in sweet basil (Ocimum basilicum), Planta, 240, 941-953, 2014.

[19] Öz M. T., Yilmaz R., Eyidoğan F., de Graaff L., Yücel M., Öktem H. A., Microarray analysis of late response to boron toxicity in barley (Hordeum vulgare L.) leaves, Turk. J. Agric. For., 33, 191-202, 2009.

[20] Kayihan C., Öz M. T., Eyidogan F., Yucel M., Öktem H. A., Physiological, biochemical, and transcriptomic responses to boron toxicity in leaf and root tissues of contrasting wheat cultivars, Plant Mol. Biol. Rep., 35, 97-109, 2017.

[21] Zhang B., MicroRNA: a new target for improving plant tolerance to abiotic stress, J. Exp. Bot., 66, 1749-1761, 2015.

[22] Ma X., Cao X., Mo B., Chen X., Trip to ER: MicroRNAmediated translational repression in plants, RNA Biol., 10, 1586-1592, 2013

[23] Jones-Rhoades M. W., Bartel D. P., Bartel B., MicroRNAs and their regulatory roles in plants, Annu. Rev. Plant Biol., 57, 19-53, 2006.

[24] Kraft E., Stone S. L., Ma L., Su N., Gao Y., Lau O. S., Deng X. W., et al., Genome analysis and functional characterization of the E2 and RING-type E3 ligase ubiquitination enzymes of Arabidopsis, Plant Physiol., 139, 1597-1611, 2005. 
[25] Liang G., Yang F., Yu D., MicroRNA395 mediates regulation of sulfate accumulation and allocation in Arabidopsis thaliana, Plant J., 62 (6), 1046-1057, 2010.

[26] Lu Y. B., Yang L. T., Qi Y. P., Li Y., Li Z., Chen Y. B., Huang Z. R., et al., Identification of boron-deficiencyresponsive microRNAs in Citrus sinensis roots by illumina sequencing, BMC Plant Biol., 14, 123, 2014.

[27] Huang J. H., Qi Y. P., Wen S. X., Guo P., Chen X. M., Chen L. S., Illumina microRNA profiles reveal the involvement of miR397a in Citrus adaptation to longterm boron toxicity via modulating secondary cell-wall biosynthesis, Sci. Rep., 6, 22900, 2016.

[28] Kramer M. F., Stem-loop RT-qPCR for miRNAs, Curr. Protoc. Mol. Biol., 95 (1), 5-10, 2011.

[29] Gautam V., Singh A., Singh S., Sarkar A. K., An efficient LCM based method for tissue specific expression analysis of genes and miRNAs, Sci. Rep., 6, 21577 , 2016.

[30] Balcells I., Cirera S., Busk P. K., Specific and sensitive quantitative RT-PCR of miRNAs with DNA primers, BMC Biotech., 11, 70, 2011.

[31] Murashige T., Skoog F., A revised medium for rapid growth and bio assays with tobacco tissue cultures, Physiol. Plant., 15, 473-497, 1962.

[32] Varkonyi-Gasic E., Wu R., Wood M., Walton E. F., Hellens R. P., Protocol: a highly sensitive RT-PCR method for detection and quantification of microRNAs, Plant Methods, 3, 12, 2007.

[33] Kayıhan D. S., Kayıhan C., Çiftçi Y. Ö., Excess boron responsive regulations of antioxidative mechanism at physio-biochemical and molecular levels in Arabidopsis thaliana, Plant Physiol. Biochem., 109, 337-345, 2016.

[34] Kozomara A., Birgaoanu M., Griffiths-Jones S., miRBase: from microRNA sequences to function, Nucleic Acids Res., 47 (D1), D155-D162, 2019.

[35] Dai X., Zhuang Z., Zhao P. X., psRNATarget: a plant small RNA target analysis server (2017 release), Nucleic Acids Res., 46 (W1), W49-W54, 2018.

[36] Mi H., Muruganujan A., Ebert D., Huang X., Thomas P. D., PANTHER version 14: more genomes, a new PANTHER GO-slim and improvements in enrichment analysis tools, Nucleic Acids Res., 47 (D1), D419D426, 2019.

[37] Llave C., Xie Z., Kasschau K. D., Carrington J. C., Cleavage of Scarecrow-like mRNA targets directed by a class of Arabidopsis miRNA, Science, 297 (5589), 2053-2056, 2002.

[38] Bartel D., MicroRNAs: genomics, biogenesis, mechanism, and function, Cell, 116 (2), 281-297, 2004.

[39] Jones-Rhoades M. W., Bartel D. P., Computational identification of plant microRNAs and their targets, including a stress induced miRNA, Mol. Cell, 14 (6), 787799, 2004
[40] Zhang B. H., Pan X. P., Wang Q. L., Cobb G. P., Anderson T. A., Identification and characterization of new plant microRNAs using EST analysis, Cell Res., 15, 336-360, 2005

[41] Hsieh L. C., Lin S. I., Shih A. C. C., Chen J. W., Lin W. Y., Tseng C. Y., Li W. H., et al., Uncovering small RNA-mediated responses to phosphate deficiency in Arabidopsis by deep sequencing, Plant Physiol., 151, 2120-2132, 2009.

[42] Wu J., Zhang Y., Zhang H., Huang H., Folta K. M., Lu J., Whole genome wide expression profiles of $\mathrm{Vi}$ tis amurensis grape responding to downy mildew by using Solexa sequencing technology, BMC Plant Biol, 10, 234, 2010.

[43] Ozhuner E., Eldem V., Ipek A., Okay S., Sakcali S., Zhang B., Boke $\mathrm{H}$., et al., Boron stress responsive microRNAs and their targets in barley, PLoS ONE, 8 (3), e59543, 2013.

[44] Huang J. H., Qi Y. P., Wen S. X., Guo P., Chen X. M., Chen L. S., Illumina microRNA profiles reveal the involvement of miR397a in citrus adaptation to long-term boron toxicity via modulating secondary cell-wall biosynthesis, Sci. Rep., 6, 22900, 2016

[45] Kayihan D. S., Kayihan C., Çiftçi Y. O., Moderate level of toxic boron causes diferential regulation of microRNAs related to jasmonate and ethylene metabolisms in Arabidopsis thaliana, Turk. J. Bot., 43, 167-172, 2019.

[46] Kepinski S., Leyser O., The Arabidopsis F-box protein TIR1 is an auxin receptor, Nature, 435 (7041), 446451, 2005.

[47] Dharmasiri N., Dharmasiri S., Estelle M., The F-box protein TIR1 is an auxin receptor, Nature, 435 (7041), 441-445, 2005

[48] Dharmasiri N., Dharmasiri S., Weijers D., Lechner E., Yamada M., Hobbie L., Ehrismann J. S., et al., Plant development is regulated by a family of auxin receptor F box proteins, Dev. Cell, 9 (1), 109-119, 2005

[49] Vidal E. A., Araus V., Lu C., Parry G., Green P. J., Coruzzi G. M., Gutierrez R. A., Nitrate-responsive miR393/AFB3 regulatory modüle controls root system architecture in Arabidopsis thaliana, Proc. Natl. Acad. Sci. USA, 107 (9), 4477-4482, 2010.

[50] Si-Ammour A., Windels D., Arn-Bouldoires E., Kutter C., Ailhas J., Meins F., Vazquez F., miR393 and secondary siRNAs regulate expression of the TIR1/AFB2 auxin receptor clade and auxin-related development of Arabidopsis leaves, Plant Physiol., 157, 683-691, 2011

[51] Chen Z. H., Bao M. L., Sun Y. Z., Yang Y. J., Xu X. H., Wang J. H., Han N., et al., Regulation of auxin response by miR393-targeted transport inhibitör response protein 1 is involved in normal development in Arabidopsis, Plant Mol. Biol., 77 (6), 619-629, 2011.

[52] Windels D., Bielewicz D., Ebneter M., Jarmolowski A., Szweykowska-Kulinska Z., Vazquez F., miR393 is required for production of proper auxin signalling outputs, PLoS One, 9, e95972, 2014. 
[53] Sunkar R., Zhu J. K., Novel and stress-regulated microRNAs and other small RNAs from Arabidopsis, Plant Cell, 16, 2001-2019, 2004.

[54] Navarro L., Dunoyer P., Jay F., Arnold B., Dharmasiri N., Estelle M., Voinnet O., et al., A plant miRNA contributes to antibacterial resistance by repressing auxin signaling, Science, 312, 436-439, 2006.

[55] Gao P., Bai X., Yang L., Lv D., Pan X., Li Y., Cai H., et al., osa-MIR393: a salinity- and alkaline stress-related microRNA gene, Mol. Biol. Rep., 38, 237-242, 2011.

[56] Bian H., Xie Y., Guo F., Han N., Ma S., Zeng Z., Wang J., et al., Distinctive expression patterns and roles of the miRNA393/TIR1 homolog modüle in regulating flag leaf inclination and primary and crown root growth in rice (Oryza sativa), New Phytol., 196, 149-161, 2012.

[57] Xia K., Wang R., Ou X., Fang Z., Tian C., Duan J., Wang Y., et al., OsTIR1 and OsAFB2 downregulation via OsmiR393 overexpression leads to more tillers, early flowering and less tolerance to salt and drought in rice, PLoS One, 7, e30039, 2012.
[58] Zhao B., Liang R., Ge L., Li W., Xiao H., Lin H., Ruan $\mathrm{K}$., et al., Identification of drought-induced microRNAs in rice, Biochem. Biophys. Res. Commun., 354, 585590, 2007.

[59] Ferreira T. H., Gentile A., Vilela R. D., Costa G. G., Dias L. I., Endres L., Menossi M., microRNAs associated with drought response in the bioenergy crop sugarcane (Saccharum spp.), PLoS One, 7, e46703, 2012.

[60] Dharmasiri S., Estelle M., The role of regulated protein degradation in auxin response, Plant Mol. Biol., 49, 401-409, 2002.

[61] Long R., Li M., Li X., Gao Y., Zhang T., Sun Y., Kang J., et al., A novel miRNA sponge form efficiently inhibits the activity of miR393 and enhances the salt tolerance and ABA insensitivity in Arabidopsis thaliana, Plant Mol. Biol. Rep., 35, 409-415, 2017. 